\title{
Smart Current Monitoring System with Relay Breaker
}

\author{
Muhammad Rusydi Muhammad Razif ${ }^{1 *}$, Aqira Azhar ${ }^{1}$, Ili Najaa Aimi Mohd Nordin ${ }^{1}$ and \\ Siti Nor Zawani Ahmmad ${ }^{2}$
}

\author{
${ }^{1}$ Faculty of Engineering Technology, Universiti Tun Hussein Onn Malaysia, Pagoh, 84600, Muar, Johor, Malaysia. \\ ${ }^{2}$ Malaysian Institute of Industrial Technology, Universiti Kuala Lumpur, Bandar Seri Alam, 81750, Masai, Johor, Malaysia. \\ *Corresponding author: rusydi@uthm.edu.my
}

\begin{abstract}
Today, the high usage of electrical home appliances has increased the domestic energy consumption. To control the consumption of domestic energy, various techniques were developed to detect current flow and to measure current consumption. Usually, a current sensor was used as a detection device and then send the data wirelessly to a centre point in the house, which is placed near to the main entrance for monitoring and controlling purposes. Wireless technology can provide better connection and reducing the need for wired connection for all power sockets in a house. The usage of LCD is to display current usage for all electrical home appliances will be more useful especially for a multi-storey house. This smart current monitoring system, will help users to monitor and control their electrical home appliances current consumption. The system will monitor each power sockets and transmit the current usage data wirelessly to a centre point which helps in reducing the time to check all the appliances.
\end{abstract}

Keywords: Current monitoring, relay breaker, wireless, residential houses, multi-storey house.

C 2019 Penerbit UTM Press. All rights reserved

Article History: received 4 September 2019; accepted 1 December 2019; published 24 December 2019.

\section{INTRODUCTION}

The development of home current usage monitoring system with relay breaker is a project that avoids wasting electricity by carelessness of user. It is also very useful in monitoring and focusing the appliances usage in the whole house especially for the multi-storey house. In domestic residential, people grown up with various types of appliances in home like computer, iron, fan and television. Lately, many electricity users complained about the rising cost of monthly electricity bill. The cost for every resident exceeded more than regular expectation. After appearance with various technology to detect current flow like current sensor, then it has come out with how to control the system for supervision current usage [1], [2]. Sometimes users turn on all appliances in one time and forget to turn off during rushing time such leaving home immediately. This will make electricity bill to increase along before user come back to turn off. Users underestimate and almost neglect regarding to this issue occur today because of their carelessness to check every time after been using the appliances. From this issues, it has been identified that the users' electricity usage in residential need to be facilitate.

Home Automation System Using Arduino Uno project is a fine combination of Android with mobile technology and embedded system. User can control home appliances by using Android mobile as long as range they can go [3][5]. An android application should be installed on users' hand phone to control several of home appliances. In addition, user can send instruction by using that an application. Usually the Bluetooth device is connected to the circuit which has a decoder. The decoder considers as microcontroller which has Arduino Uno. Bluetooth module such as HC-05, supports master and slave mode [6], [7] for serial communication (9600-11520 bps) SPP and UART interface [8], [9]. Using these features as stated by researcher [3], it can communicate with other Bluetooth enabled devices like mobile phones and laptops.

Another project which is the title called Use of Arduino Board in Android for Home Appliances [10] used 8 channel relay as interconnected to the load. A relay channel is a presumably model of the communication between a sender and a receiver as aided by one or more intermediate relay nodes. This is a 8 Channel Relay module, it can be controlled directly in range of microcontrollers such as Arduino Uno. A relay is usually a mechanical device that motivated by associate degree electrical current [11]. Relays are same with remote switches and it employed in several applications due to their relative simplicity, long life, and tested high dependability. Within the home, relays are always employed in refrigerators, laundry machines and dishwashers, and heating and air-conditioning controls.

The monitoring is essential when working in the field of three phase system. Some of users and companies using smart monitoring software programs to dealing with daily work. The Smart Voltage and Current Monitoring for Three Phase Inverters Using an Android Smartphone Application has designed to monitor the performance of a three phase grid by measuring voltage and current every 
phases which is three phase [5], [10]. The system has been designed using Arduino Nano V3.0 as microcontroller circuit to read and calculate the RMS voltage and current from sensor units. The dimension for Arduino Nano [12] is only $43 \mathrm{~mm} \times 18 \mathrm{~mm}$, it comes with $6 \mathrm{PWM} \mathrm{I} / \mathrm{O}$ from the total of 14 digitals I/O, 8 analog inputs, $16 \mathrm{MHz}$ clock speed and $32 \mathrm{kB}$ of flash memory The current sensor unit designed based on the ACS712 chip (surface mount technology). Instead of using the standard USB to connect to the computer, it uses the mini USB but without any the power plug for external power source that build on Arduino Uno.

The system design preferred immobile because of easier connection [13] and avoidance from interruption such as low battery [14] or smartphone application problem. User may interact with LCD indication for monitoring current usage and relay switch as a breaker system that are fixed nearest the exit door. Hence, if this system applies to residential in future, probably users will more alert to the surrounding regarding to the appliances or current consumption. This application will turn off any switch automatically for temporary if users detect current use before they leave their home. In addition, this intelligent technology will monitor every plug point of every floor in the house wirelessly. The combination with wireless will easily to construct without the need of long wiring connection and only the Bluetooth system will transmit data in the range specified [15] with low energy usage [16]-[20].

\section{METHODOLOGY}

The whole process of Smart Current Monitoring System of the system encompassed with three stages which are input, process and output. Input classified as the initial process of the system which initiate the whole process. There are three blocks presented which are breaker 1, breaker 2 and power supply. The second part involve with a lot of block namely Arduino Uno, current sensors ACS712ELCTR30A-T, Bluetooth module and relays. Arduino Uno act as the microcontroller which control the whole system process. Similar four Bluetooth modules interconnected each other which assigned as Bluetooth (Master) 1 and Bluetooth (Slave) 1 for current reading and Bluetooth (Master) 2 and Bluetooth (Slave) 2 for high and low condition switch (breaker). At the same time, all loads connected in series with current sensors ACS712ELCTR30A-T and relays. As long as load connected between them, current consumption will be measured by current sensors ACS712ELCTR-30A-T. Last part presents the value of Alternating Current (AC) from the loads on LCD.

The purpose of using LCD is to provide display of current consumption while circuit in operation. Figure 1 shows the block diagram which simplify the whole process of actual process. In the process stage, the current value will be measured and then transmitted wirelessly through Bluetooth 1 and Bluetooth 2. The process is controlled by Arduino Uno and it has been programmed using Arduino Software (IDE) [14]. All writing command codes in C++ language and the output system merely can be read as digital. However, sensor input in this project measured by current sensors ACS712ELCTR-30A-T will be regulated to digital signal and displayed in LCD.

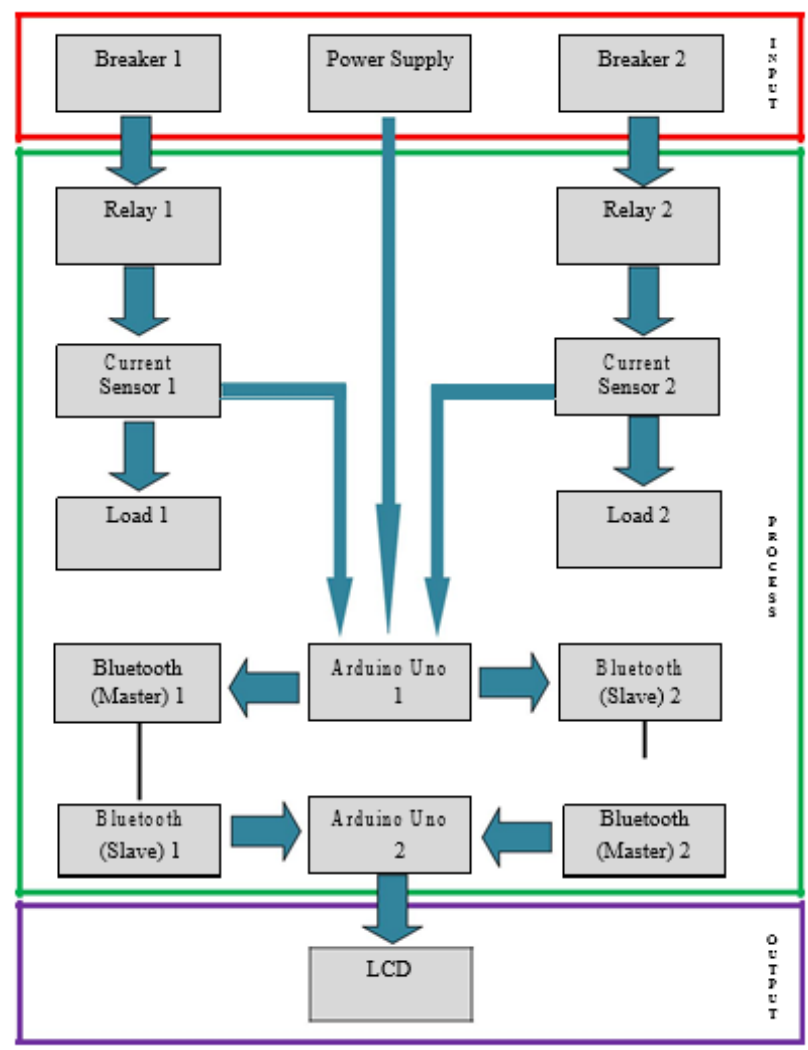

Figure 1. Block diagram of development of home current usage monitoring with relay breaker system

The Arduino Software (IDE) is used to simulate command codes and inspect any error occurrence, because it is easier in scanning specific program error line and it has provided serial communication which it can observed output value devoid of hardware. The Bluetooth system used in the smart current monitoring system has Master and Slave mode, with the different baud rate 38400 for default setting and normal system. The LCD display is an output of home current usage monitoring with relay breaker system to display load reading from the input. First part started with $4 \times 20$ LCD display directly connected to the Arduino Uno. Potentiometer $(50 \mathrm{k})$ is used in the liquidcrystal display testing to control backlight during appearance character on LCD display. This method is to have multi-condition of backlight. The first line of the LCD will display current consumption on the load on the first floor, whereas the second line of the LCD will present current consumption on the ground floor. Figure 2 shows the double input reading of current consumption in both floors.

This project use two set of Bluetooth module denoted by Master and Slave. Bluetooth module has been built specially for wireless communication. However, Bluetooth module has limitation in term of range distance that mere provided about 30 feet range. If the range is more than 30 feet, it would be intermittent the reading system. The Bluetooth has been configured earlier before use. After configuration process of both module, successful condition will be indicated by small LED on module with 2 seconds interval blinking. Since the small LED indicator indicate 
successful configuration, it automatically pairing with each other by switching off and re-connect again supply to module.

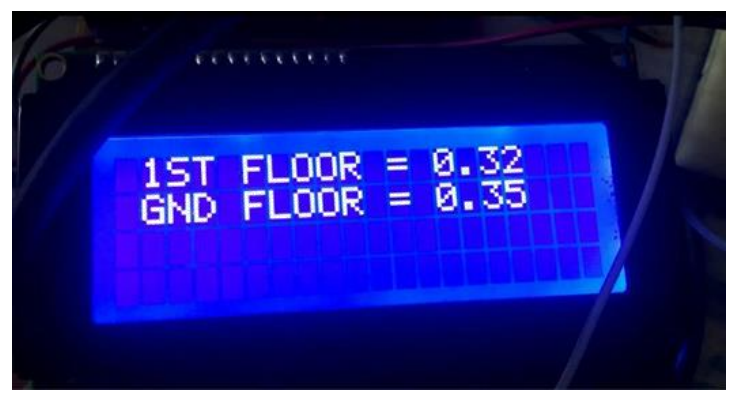

Figure 2. Double input reading use $4 \times 20$ LCD

The implementation of relay breaker system is used to cut off a current flowing through appliances. The conceptual of breaker system used HIGH/LOW condition from the LED rocker switch. The rocker switch has indicated the activation of $\mathrm{HIGH} / \mathrm{LOW}$ condition. Pins switch have been checked to ensure that each of the pins are connected properly. During switch OFF, pin signal and ground must be connected using $1 \mathrm{k}$ resistor. If the switch goes to $\mathrm{ON}$, then $\mathrm{VCC}$ will provides $+5 \mathrm{~V}$ to pin signal. These methods must be use to prevent the switch to vary as floating switch. In other words, floating switch will encounter interruption which is goes interchangeable to $\mathrm{HIGH} / \mathrm{LOW}$. Connection switch and all circuits have been tested its functionality and they have been merged on a Perspex home design as a prototype of double-storey home. Figure 3 shows the complete cross sectional home model.

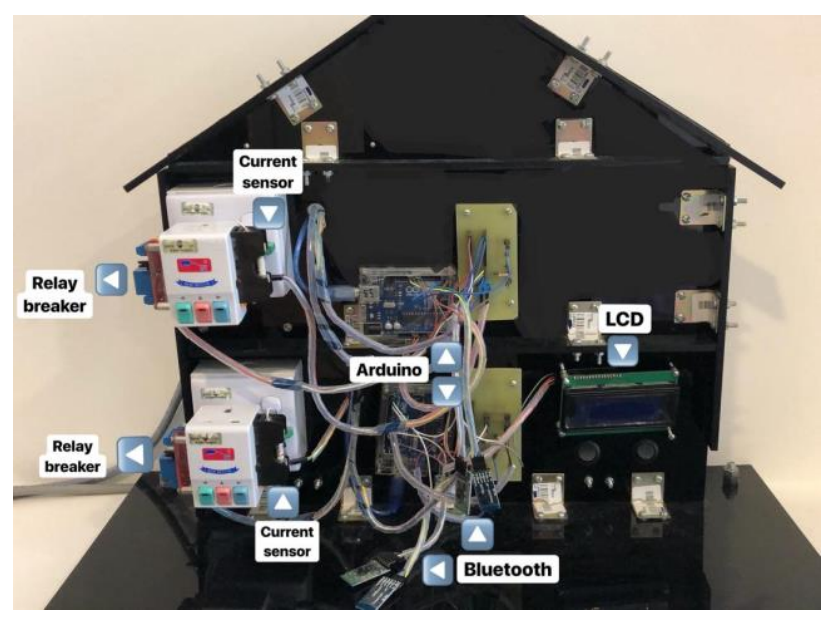

Figure 3. Finalize product constructed

\section{RESULTS AND DISCUSSION}

Development of home current usage monitoring with relay breaker system focuses on three results which are Bluetooth range reading, display of current consumption on LCD and relay breaker system result.

In Bluetooth current reading transmission data, the challenge is to ensure the current reading measurements are not exceeding the Bluetooth maximum operational range. The maximum Bluetooth operational range is important because it will affect the efficiency on the system while working. Moreover, the purpose of Bluetooth range reading is to estimate location of Bluetooth transmitter at plug point and the Bluetooth receiver near to the LCD display. Bluetooth module also should have adequate current rate, otherwise system connection will break and could cause lost pairing between two modules.

Table 1 shows the result of the Bluetooth range test for hair dryer load. Starting from 3 meter to 9 meter, all reading remain constant about $3.92 \mathrm{~A}$ with less than 0.06 A differences. This indicate that the system function well and stable within this range. The reading measured started to interrupt after the distance is more than 12 meter onwards as presents in the Table 1 .

Table 1. Hair dryer Bluetooth range reading

\begin{tabular}{|c|c|}
\hline Range (meter) & Load Reading (Hair Dryer) (A) \\
\hline 3 & 3.92 \\
\hline 6 & 3.90 \\
\hline 9 & 3.96 \\
\hline 12 & 0.18 \\
\hline 15 & 0.20 \\
\hline
\end{tabular}

Table 2 shows the result of current usage for several appliances when been turn on and off. The aim of the testing is to compare the current value output when the relay switch is turn on and off and to observe the accuracy of the reading by the current sensor. From the Table 2, water heater shows the highest current usage with $8.5 \mathrm{~A}$ followed by Multicooker Iron and hair dryer with $6.83 \mathrm{~A}$, $4.92 \mathrm{~A}$ and $3.92 \mathrm{~A}$ respectively when the relay switch is turn $\mathrm{ON}$. Table fan and phone charger shows low current consumption with $0.44 \mathrm{~A}$ and $0.37 \mathrm{~A}$ respectively. From the current consumption reading, estimated power usage in unit Watt can be computed by multiply the current reading with 240 Voltage.

Table 2. Comparison of the current value when relay switch is on and off

\begin{tabular}{|c|c|c|}
\hline \multirow{2}{*}{ Appliances } & \multicolumn{2}{|c|}{ Current Value (A) } \\
\cline { 2 - 3 } & $\begin{array}{c}\text { Relay Switch } \\
\text { OFF }\end{array}$ & $\begin{array}{c}\text { Relay Switch } \\
\text { ON }\end{array}$ \\
\hline Hair dryer & 0.29 & 3.92 \\
\hline Table fan & 0.21 & 0.44 \\
\hline Water heater & 0.24 & 8.50 \\
\hline Iron & 0.24 & 4.92 \\
\hline Phone charger & 0.26 & 0.37 \\
\hline Multicooker & 0.29 & 6.83 \\
\hline
\end{tabular}


Figure 4 shows the LCD display of current reading when the relay is switch off at the ground (GND) floor and the 1 st floor. For example, the ground floor is connected with water heater and the 1 st floor is connected with multicooker. As can be seen, both of the reading displayed $0.26 \mathrm{~A}$ when the relay switch is turned off. If the reading is below $0.30 \mathrm{~A}$, that indicate the relay switch is turn off and no load is connected. After the relay switch is turn on, LCD will display the current usage of multicooker on the first floor and current usage of water heater on the ground floor as in Figure 5.

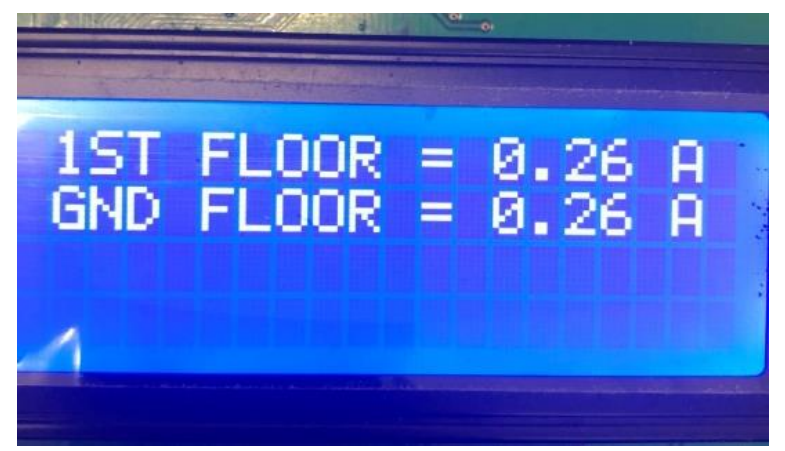

Figure 4. Current reading (A) when relay switch is on

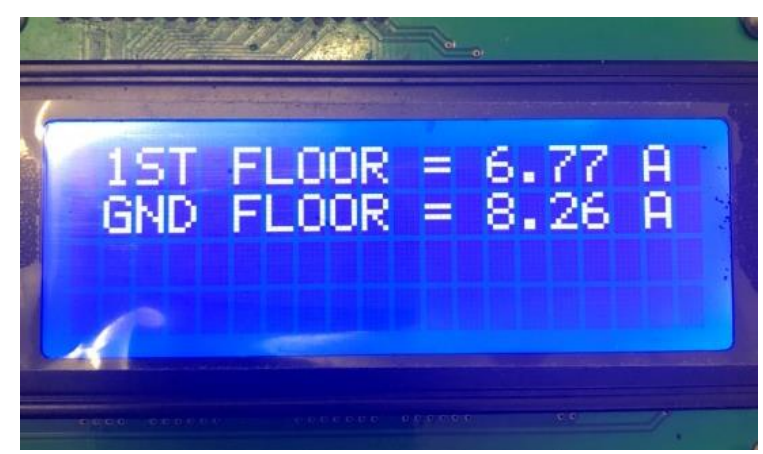

Figure 5. Current reading (A) when relay switch is off

The relay breaker system was built with single purpose which is to disconnect undesired load in the house at one central switch. Therefore, the result was recorded to present functionality of the relay breaker system through circuit indication with two condition switches and relay module as shown in the Figure 6 . When the relay module only indicates green LED that means the relay switch is in off mode.

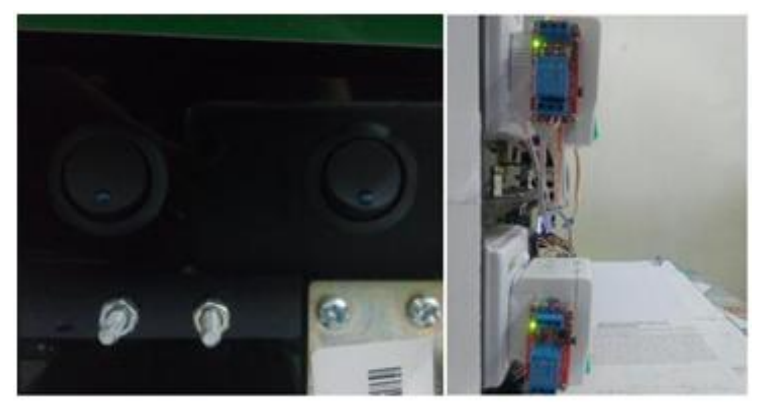

Figure 6. Condition of relay breaker system when is not trigger (non-receive signal)

Figure 7 shows the red LED indicates together with green LED meaning that the relay switch is in on mode and trigger the relay module. When the relay switch is turned on, there is no current flow towards the load.

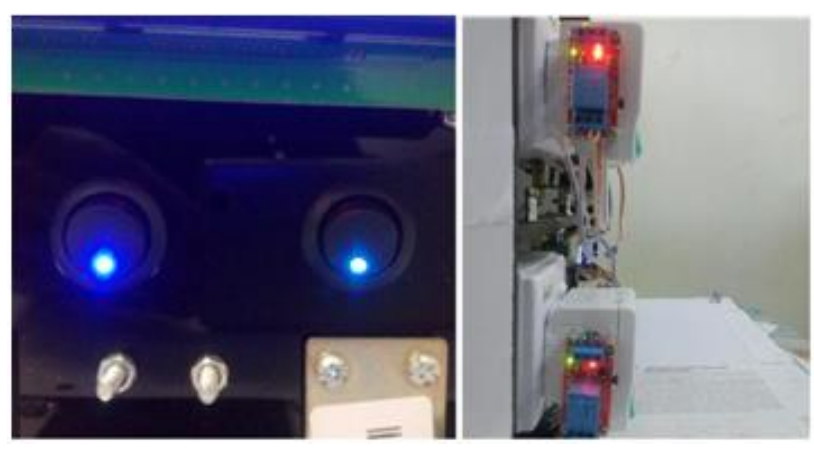

Figure 7. Condition of relay breaker System while triggered (received signal)

\section{CONCLUSION}

The development of smart current monitoring with relay breaker system was successfully implemented. To summarize, this project has successfully achieved the objectives to monitor the current usage or appliances and turning on/off all appliances at one centre point, near to the main home entrance. The prototype is able to be implemented to preserve small energy wastage that can cause high bill cost in a long term per annum by negligent users. The relay breaker system with one central switch to break current flow to appliances is really helpful as it can be switch off directly without having to go back to the switched on plug.

\section{ACKNOWLEDGMENT}

This research is fully supported by TIER 1 grant, H136. The authors fully acknowledged Ministry of Higher Education (MOHE) and Universiti Tun Hussein Onn Malaysia for the approved fund which makes this important research viable and effective.

\section{REFERENCES}

[1] Khair, Ummul, A. J. Lubis, I. Agustha and M. Zulfin, "Modeling and simulation of electrical prevenion system using Arduino Uno, GSM modem, and ACS712 current sensor," in Journal of Physics: Conference Series, vol. 930, no. 1, p. 012049. IOP Publishing, 2017.

[2] P. Gao, S. Lin, and W. Xu, "A novel current sensor for home energy use monitoring," in IEEE Trans. Smart Grid, vol. 5, no. 4, pp. 2021-2028, 2014.

[3] M. K. Swain, S. Mahato, R. K. Verma and K. D. Mahto, "Home automation using Arduino Uno," in International Journal of Application or Innovation in Engineering \& Management (IJAIEM), vol. 6, no. 2, pp. 41-44, 2017.

[4] Klemenjak, Christoph, D. Egarter, and W. Elmenreich, "YoMo: The Arduino-based smart metering board," in Computer Science-Research and Development 31, no. 1-2 (2016): 97-103.

[5] M. J. Mnati, R. F. Chisab, and A. V. D. Bossche, "A smart distance power electronic measurement using smartphone applications," in in 2017 19th European 
Conference on Power Electronics and Applications (EPE'17 ECCE Europe), pp. P-1. IEEE, 2017.

[6] M. R. Kannan, M. M. Sreekanth, V. Sivanantham, K. S. Kumar, S. Ghanta, P. Surya Teja and Rajesh G. Reddy, "Integration of haptics in agricultural robotics." in IOP Conference Series: Materials Science and Engineering, vol. 225, no. 1, p. 012203. IOP Publishing, 2017.

[7] Mishra, Shubham, S. Takkar, T. Garg, A. Kaur, P. Rakheja and Charu Rana, "Arduino based gestures to speech conversion system," in International Journal 6, no. 1 (2018): 159-160.

[8] M. Saritha and N. Kalpana, "Development of remote buttons in Android app ( bluetooth ) to control a robo," in International Journal of Engineering Science, vol. 7, no. 7, pp. 13775-13777, 2017.

[9] S. Kalaiarasi, Y. Trivedi, S. Banerjee, N. Chaturvedi and U. G. Scholar, "Gesture control robot using accelerometer and voice control for the blind," in International Journal of Engineering Science, vol. 16800, no. 4, pp. 16800-16803, 2018.

[10] S. L. Farpat, S. S. More and S. D. Takwale, "A review : Use of Arduino board in android for home appliances," in J. Embed. Syst. Process., vol. 2, no. 1, pp. 1-11, 2017.

[11] Fernández, Manuel, X. Perpiñà, J. Rebollo, M. Vellvehi, D. Sánchez, T. Cabeza, S. Llorente and X. Jordà, "Solid-state relay solutions for induction cooking applications based on advanced power semiconductor devices." in IEEE Transactions on Industrial Electronics 66, no. 3 (2019): 1832-1841.

[12] S. Sahu, D. Paul and S. Senthilmurugan, "Density based traffic signal system," in International Journal of Innovative Research in Science, Engineering and Technology 3, no. 3 (2014): 2218-2222.
[13] N. Kaur and S. Monga, "Comparsions of wired and wireless networks: A review," in International Journal of Advanced Engineering Technology 5, no. 2 (2014): 34-35.

[14] S. A. Arduino, "Arduino," in Arduino LLC (2015).

[15] R. Pahuja and N. Kumar, "Android mobile phone controlled Bluetooth robot using 8051 microcontroller," in International Journal of Scientific Engineering and Research 2, no. 7 (2014): 14-17.

[16] S. M. Darroudi and C. Gomez, "Bluetooth low energy mesh networks: A survey," in Sensors, vol. 17, no. 7, p. 1467, 2017.

[17] A. Montanari, S. Nawaz, C. Mascolo and K. Sailer, "A study of Bluetooth low energy performance for human proximity detection in the workplace," in 2017 IEEE International Conference on Pervasive Computing and Communications (PerCom), pp. 9099. IEEE, 2017.

[18] S. Kamath and J. Lindh, "Measuring Bluetooth® low energy power consumption," in Texas instruments application note AN092, Dallas (2010).

[19] Kuo, Feng-Wei, S. B. Ferreira, H. N. R. Chen, L. C. Cho, C. P. Jou, F. L. Hsueh, Madadi, I., Tohidian, M., Shahmohammadi, M., Babaie, M. and Staszewski, R.B., "A Bluetooth low-energy transceiver with 3.7-mW all-digital transmitter, 2.75 $\mathrm{mW}$ high-IF discrete-time receiver, and TX/RX switchable on-chip matching network," in IEEE Journal of Solid-State Circuits 52, no. 4 (2017): 1144-1162.

[20] H. Chu and M. Chien, "An adaptive Bluetooth low energy positioning system with distance measurement compensation," in International Conference on Mobile and Wireless Technology, pp. 223-234. Springer, Singapore, 2018 pp. 1-10. 